\title{
Mechanisms of Gastric Mucus Secretion from Cultured Rat Gastric Epithelial Cells Induced by Carbachol, Cholecystokinin Octapeptide, Secretin, and Prostaglandin $\mathrm{E}_{2}$
}

\author{
Satoru Tani, ${ }^{*, a, b}$ Teruo Suzuki, ${ }^{a}$ Sayuri Kano, ${ }^{a}$ Toru Tanaka, ${ }^{a}$ Katsuyosi Sunaga, ${ }^{a}$ \\ Rie Morishige, ${ }^{a}$ and Tadashi Tsuda ${ }^{a}$ \\ Faculty of Pharmaceutical Sciences ${ }^{a}$ and Life Science Research Center, ${ }^{b}$ Josai University, 1-1 Keyaki-dai, Sakado, Saitama \\ 350-0295, Japan. Received July 4, 2001; accepted October 1, 2001
}

The effects of carbachol, cholecystokinin octapeptide (CCK-8), secretin, prostaglandin $\mathrm{E}_{2}\left(\mathrm{PGE}_{2}\right)$, and second mediator-like substances (A23187, phorbol 12-myristate 13-acetate, and dibutyryl cAMP) on mucus secretion from cultured gastric epithelial cells were investigated. Gastric mucus was measured by an enzyme-linked lectin assay with soybean agglutinin and wheat germ agglutinin. Intracellular cAMP and $\mathrm{Ca}^{2+}$ were measured with a cAMP assay kit and an image analysis system using fura-2-loaded cells, respectively. Secreted mucus induced by any combination of receptor agonists was almost equal to the summation of each stimulated mucus secretion. On the other hand, combined stimulation with second mediator-like substances secreted mucus synergistically. These results suggest the existence of interactions among receptors for mucus secretion. Based on these results, the secretagogue induced intracellular cAMP and free calcium $\left(\left[\mathrm{Ca}^{2+}\right]_{\mathrm{i}}\right)$ levels were measured in cultured gastric epithelial cells incubated with secretagogues. Secretin and $\mathrm{PGE}_{2}$ induced cAMP accumulation, and carbachol and CCK-8 induced a $\left[\mathrm{Ca}^{2+}\right]_{i}$ increase. To confirm these results, the effects of protein kinase $\mathrm{A}$ and $\mathrm{C}$ inhibitors and intracellular calcium chelator on mucus secretion were investigated. An intracellular calcium chelator inhibited the mucus secretion induced not only by carbachol and CCK-8 but also by secretin and PGE . These results suggest that the $\left[\mathrm{Ca}^{2+}\right]_{i}$ plays an important role in mucus secretion through cAMP accumulation.

Key words gastric epithelial cell; mucus secretion; intracellular free calcium; protein kinase C; cAMP

Gastric mucus is secreted to form a gel layer on the gastric mucosa, which acts as a lubricant for ingested food and protects against injury from digestive juice, alcohol, hypertonic or hypotonic foods, spices, drugs, etc. However, even in the absence of food in the stomach, the gastric mucosa should be coated with mucus against unexpected invasions. Therefore it is thought that gastric mucus secretion is controlled by many factors in different ways. Prostaglandin $\mathrm{E}_{2}\left(\mathrm{PGE}_{2}\right)$ and secretin, which are known inhibitors of gastric acid secretion, stimulate mucus secretion. ${ }^{1,2)}$ Generally, gastric mucus is secreted via two or three pathways ${ }^{3)}$ : receptor-mediated exocytosis; apical expulsion; and possibly exfoliation. In receptormediated mucus secretion, many physiologically active substances including neurotransmitters, autacoids, hormones, and their related substances are known to be secretagogues. ${ }^{3)}$ We have reported that carbachol, cholecystokinin octapeptide (CCK-8), secretin, and PGE $_{2}$ strongly stimulated mucus secretion from cultured rat gastric epithelial cells and gastrin I stimulated it weakly, but histamine did not. ${ }^{1)}$ Although secretagogues of mucus secretion resemble those of gastric acid and pepsinogen secretion, the functions of secreted substances are different; gastric acid and pepsinogen are used for digestion, but mucus protects the gastric mucosa. If the regulatory systems of gastric acid, pepsinogen, and mucus secretion were completely the same, digestion in the stomach would be unsuccessful. Since common secretagogues stimulate secretion by specific cells, the different regulatory mechanisms of secretion must work in each type of cell. However, the signal transduction mechanisms of gastric mucus secretion in the rat are obscure. Candidates for the second mediators have been reported to be $\mathrm{cAMP}{ }^{4)}$ phosphatidylinositol (PI) turnover $\left(\mathrm{Ca}^{2+}\right.$ and protein kinase $\left.\mathrm{C}\right),{ }^{5)}$ guanosine $3^{\prime}, 5^{\prime}$ cyclic monophosphate, ${ }^{6}$ and nitric oxide. ${ }^{6)}$ To clarify the signal transduction mechanisms of receptor-mediated exocyto- sis, we focused on cAMP and PI turnover. Although it is known that cAMP accumulation and PI turnover are related to mucus secretion, no direct results have been obtained in the rat. In this paper, we investigate the mucus secretion through cAMP accumulation and PI turnover.

\section{MATERIALS AND METHODS}

Materials Soybean agglutinin (SBA), biotinylated goat anti-SBA, and horseradish peroxidase-avidin D (HRP-avidin D) were purchased from Vector Laboratories, Inc. (Burlingame, CA, U.S.A.). Carbamylcholine chloride (carbachol) and bovine serum albumin (BSA) were purchased from Sigma Chemical Co. (St. Louis, MO, U.S.A.). CCK-8 and secretin were from Peptide Institute Inc. (Osaka, Japan). $\mathrm{PGE}_{2}$ and $N$-[2-( $p$-bromocinnamylamino)ethyl]-5-isoquinolinesulfonamide (H-89) were from BIOMOL Research Laboratories Inc. (Plymouth Meeting, MA, U.S.A.). A23187, phorbol 12myristate 13-acetate (PMA), and dibutyryl cAMP (dbcAMP) were from Wako Pure Chemical Industries Ltd. (Osaka, Japan). Chelerythrine chloride was from Research Biochemicals International (Natick, MA, U.S.A.). Fura-2(acetoxymethyl ester) (fura-2-AM) and 1,2-bis(2-aminophenoxy)ethane- $N, N, N^{\prime}, N^{\prime}$-tetraacetic acid tetrakis(acetoxymethyl ester)(BAPTA-AM) were purchased from Dojindo Laboratories (Kumamoto, Japan). All other reagents were of the best commercial quality available.

Isolation and Culture of Rat Gastric Epithelial Cells Rat gastric epithelial cells were obtained by the previously established method. ${ }^{1)}$ Briefly, the stomach from an anesthetized male Wistar rat was everted and rinsed with ice-cold phosphate-buffered saline. The everted sac of the stomach was filled with medium $\mathrm{B}\left(1.0 \mathrm{mM} \mathrm{CaCl}_{2}, 1.5 \mathrm{mM} \mathrm{MgCl}_{2}\right.$, and $0.1 \% \mathrm{BSA}$ in medium $\mathrm{A}$ instead of $1.0 \% \mathrm{BSA})$, immersed 
in medium A $\left(0.5 \mathrm{~mm} \mathrm{NaH} \mathrm{PO}_{4}, 1 \mathrm{~mm} \mathrm{Na} \mathrm{HPO}_{4}, 20 \mathrm{~mm}\right.$ $\mathrm{NaHCO}_{3}, 70 \mathrm{~mm} \mathrm{NaCl}, 5.0 \mathrm{~mm} \mathrm{KCl}, 11 \mathrm{~mm}$ glucose, $25 \mathrm{~mm}$ HEPES, and $1.0 \%$ BSA [pH 7.3]) containing Dispase I (1000 U/ml) (Godo-Shusei Co., Tokyo, Japan), and gassed with $95 \% \mathrm{O}_{2}$ and $5 \% \mathrm{CO}_{2}$ at $37^{\circ} \mathrm{C}$ for $1 \mathrm{~h}$. The stomach was transferred to medium A with $0.5 \mathrm{~mm}$ EDTA. Mucosal cells were gently isolated by pipetting from the surface of the gastric mucosa and filtered through a 150-mesh nylon filter. Cells were collected by centrifugation at $50 \times \boldsymbol{g}$ for $3 \mathrm{~min}$ and resuspended in medium $B$. The surface epithelial cells were separated as a precipitate by density gradient centrifugation with 15\% Percoll (Amersham Pharmacia Biotech, Uppsala, Sweden) at $300 \times \boldsymbol{g}$ for $5 \mathrm{~min}$. Obtained cells were inoculated onto plastic dishes (35 $\mathrm{mm}$ in diameter) coated with collagen gel $\left(2 \times 10^{6}\right.$ cells/dish $)$ and cultured in a mixture of Dulbecco's modified Eagle's minimum essential medium and Ham's F-12 (1:1) supplemented with $10 \%$ fetal calf serum (FCS) and gentamicin sulfate $100 \mu \mathrm{g} / \mathrm{ml}$ at $37^{\circ} \mathrm{C}$ in a $\mathrm{CO}_{2}$ incubator.

Protocol of Mucus Secretion Experiment On day 2 after inoculation ( $2 \mathrm{~d}$ of culture) of epithelial cells, the dishes were washed with medium $\mathrm{B}$ and preincubated with medium $\mathrm{B}$ for $15 \mathrm{~min}$ at $37^{\circ} \mathrm{C}$ in a $\mathrm{CO}_{2}$ incubator. Then epithelial cells were incubated with the secretagogue in the culture medium for $60 \mathrm{~min}$ in a $\mathrm{CO}_{2}$ incubator. After mixing by gently inclining the dishes, an aliquot of culture medium was collected for mucus measurement. Total mucus was measured after sonication of the frozen and thawed cells.

Measurement of Gastric Mucus An enzyme-linked lectin assay (ELLE) was used for the measurement of mucus. Soybean agglutinin-coated microwell plates and biotinylated wheat germ agglutinin were used for this assay. Staining was developed by avidin-peroxidase complex with $0.03 \% \mathrm{H}_{2} \mathrm{O}_{2}$ and 3-amino 9-ethylcarbazole as a chromophore.

Measurement of Intracellular CAMP Cells that had been cultured for $2 \mathrm{~d}$ and washed were incubated with a secretagogue in the presence of 3-isobutyl 1-methylxantine (IBMX) $\left(1 \times 10^{-4} \mathrm{M}\right)$ at $37^{\circ} \mathrm{C}$ for $10 \mathrm{~min}$. After discarding the incubation medium, $6 \%$ trichloroacetic acid (TCA) was added to the culture dishes. The samples for cAMP measurement were prepared after exclusion of TCA with ethyl ether from the supernatant collected by centrifugation. Contents of cAMP in the samples were measured using a cAMP enzyme immunoassay system (Amersham, Buckingham, U.K.).

Measurement of Intracellular Free Calcium For the measurement of the concentration of intracellular free calcium $\left(\left[\mathrm{Ca}^{2+}\right]_{\mathrm{i}}\right){ }^{7)}$ epithelial cells $\left(1 \times 10^{5}\right.$ cell/dish $)$ were inoculated on the glass base dish (Iwaki Glass, Tokyo, Japan) coated with collagen gel so as to form small cell layers. The cultured cells were incubated with well-dispersed fura-2-AM $(5 \mu \mathrm{M})$ for $60 \mathrm{~min}$ and washed with culture medium. The fura-2-loaded cells in the dish were placed on a microscopic stage and incubated with culture medium containing a secretagogue. Fluorescence at $510 \mathrm{~nm}$, excited at 340 and $380 \mathrm{~nm}$ alternatively, was recorded with a SIT camera (Hamamatsu Photonics, Hamamatsu, Japan) and analyzed using the ARGUS 50/Ca image analysis system (Hamamatsu Photonics).

Statistical Analysis Data were analyzed using Student's $t$-test for paired comparisons. The statistical significance of the difference between basal values and stimulated ones in the dose-response curves was determined by the analysis of variance.

\section{RESULTS}

Interactions among Some Secretagogues in Stimulation of Mucus Secretion The effects of carbachol, secretin, CCK-8, $\mathrm{PGE}_{2}$, and each paired combination on mucus secretion from cultured gastric epithelial cells were examined (Table 1). Based on the dose-response relationships, the submaximal dose of each secretagogue was used in this study. Mucus secretion induced by any combination of two secretagogues was almost equal to the summation of mucus secretion induced by each secretagogue. Therefore mucus was additively secreted by the simultaneous administration of each pair of these secretagogues.

Effects of Second Mediator-Like Substances on Mucus Secretion The effects of dose-response relationships of the second mediator-like substances A23187, PMA, forskolin, and cAMP on mucus secretion from the cultured gastric epithelial cells were examined. Mucus secretion was strongly stimulated by A23187 and PMA in a dose-dependent manner and weakly stimulated by forskolin and dbcAMP (Fig. 1). We also investigated the effects of combined administration of second mediator-like substances on mucus secretion. To induce approximately $10 \%$ of total and significant mucus secretion, we chose $5 \times 10^{-7}, 1 \times 10^{-9}$, and $1 \times 10^{-3} \mathrm{M}$ as the

Table 1. Interactions among Carbachol, CCK-8, Secretin, and $\mathrm{PGE}_{2}$ on Mucus Secretion from Cultured Gastric Epithelial Cells

\begin{tabular}{lc}
\hline \hline \multicolumn{1}{c}{ Secretagogue } & Mucus secretion (\% total) \\
\hline Basal & $2.20 \pm 0.42$ \\
Carbachol $\left(5 \times 10^{-5} \mathrm{M}\right)$ & $7.25 \pm 0.68$ \\
CCK-8 $\left(1 \times 10^{-9} \mathrm{M}\right)$ & $7.33 \pm 1.17$ \\
Secretin $\left(1 \times 10^{-9} \mathrm{M}\right)$ & $8.15 \pm 0.48$ \\
PGE $\left(1 \times 10^{-9} \mathrm{M}\right)$ & $8.45 \pm 0.56$ \\
Carbachol + CCK-8 & $11.25 \pm 1.35$ \\
Carbachol+Secretin & $13.63 \pm 1.76$ \\
Carbachol+PGE & $14.73 \pm 0.37$ \\
CCK-8+Secretin & $12.00 \pm 0.45$ \\
CCK-8+PGE & $11.36 \pm 0.48$ \\
Secretin + PGE $_{2}$ & $13.20 \pm 0.59$ \\
\hline
\end{tabular}

Each value is the mean \pm S.E. of 3 separate experiments.

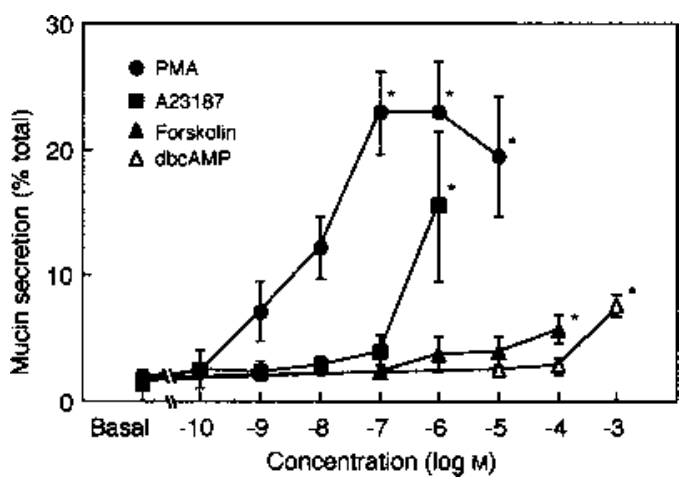

Fig. 1. Dose-Response Relationships of PMA, dbcAMP, and A23187 on Mucus Secretion from Cultured Gastric Epithelial Cells

Mucus secretion was expressed as a percentage of the total mucus that was estimated after freezing and thawing of cultured cells. Each value is the mean \pm S.E. of 5 separate experiments. $* p<0.01$ 
Table 2. Interactions among A23187, PMA, and dbcAMP on Mucus Secretion from Cultured Gastric Epithelial Cells

\begin{tabular}{lc}
\hline \multicolumn{1}{c}{ Secretagogue } & Mucus secretion (\% total) \\
\hline Basal & $4.47 \pm 0.83$ \\
A23187 $\left(5 \times 10^{-7} \mathrm{M}\right)$ & $9.14 \pm 0.63$ \\
PMA $\left(1 \times 10^{-9} \mathrm{M}\right)$ & $10.66 \pm 0.75$ \\
dbcAMP $\left(1 \times 10^{-3} \mathrm{M}\right)$ & $7.46 \pm 0.79$ \\
A23187+PMA & $20.64 \pm 1.30$ \\
A23187+dbcAMP & $17.01 \pm 2.06$ \\
PMA+dbcAMP & $24.60 \pm 1.32$ \\
A23187+PMA+dbcAMP & $34.67 \pm 5.07$ \\
\hline
\end{tabular}

Each value is the mean \pm S.E. of 3 separate experiments.
Table 3. Effects of Secretagogues on cAMP Accumulation in Cultured Gastric Epithelial Cells

\begin{tabular}{ll}
\hline \hline \multicolumn{1}{c}{ Secretagogue } & cAMP $(\mathrm{pm} / \mathrm{dish})$ \\
\hline Basal & $0.14 \pm 0.04$ \\
Forskolin $\left(1 \times 10^{-4} \mathrm{M}\right)$ & $0.89 \pm 1.71^{* *}$ \\
Secretin $\left(1 \times 10^{-8} \mathrm{M}\right)$ & $0.54 \pm 0.18^{*}$ \\
PGE $_{2}\left(1 \times 10^{-7} \mathrm{M}\right)$ & $0.77 \pm 0.06^{* *}$ \\
CCK-8 $^{*}\left(1 \times 10^{-7} \mathrm{M}\right)$ & $0.17 \pm 0.10$ \\
Carbachol $\left(1 \times 10^{-4} \mathrm{M}\right)$ & $0.17 \pm 0.07$ \\
\hline
\end{tabular}

Each value is the mean \pm S.E. of 5 separate experiments. Gastrin $\mathrm{I}\left(1 \times 10^{-7} \mathrm{M}\right)$ and histamine $\left(1 \times 10^{-5} \mathrm{M}\right)$ did not stimulate cAMP accumulation. $* p<0.05 ; * * p<0.01$.
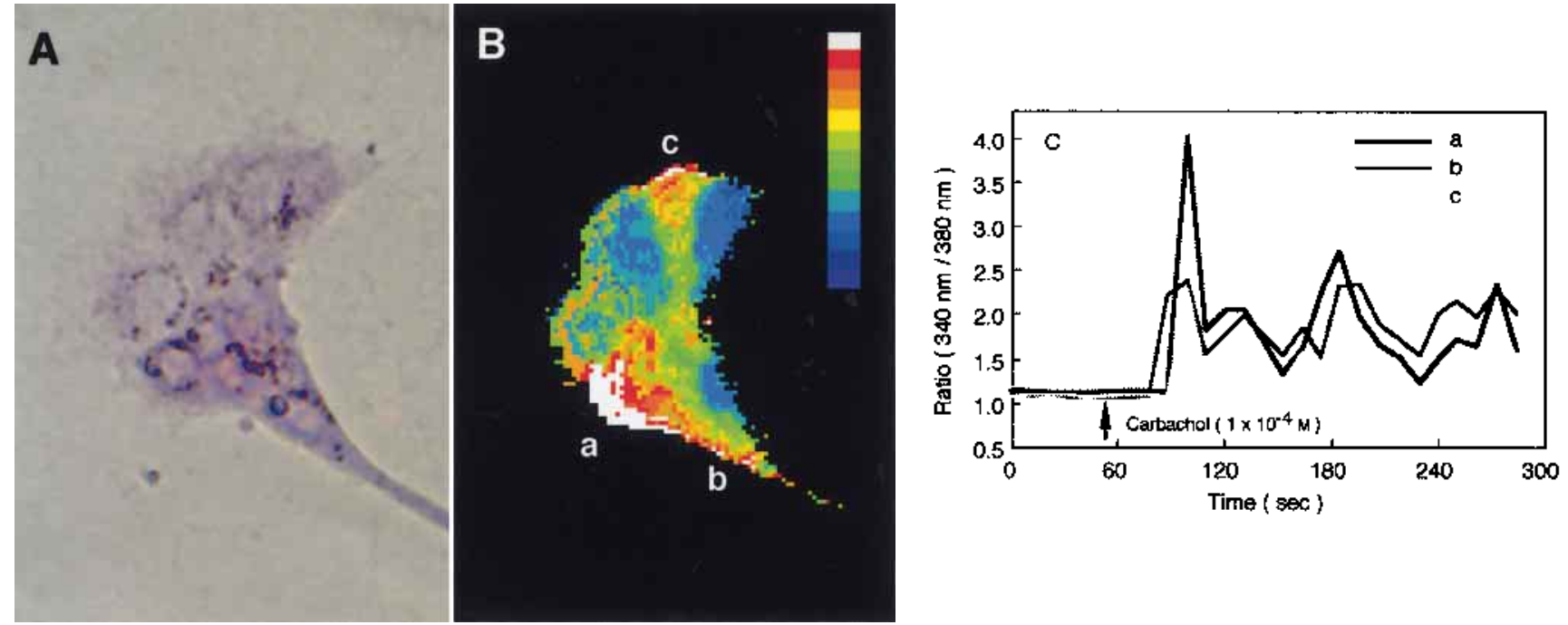

Fig. 2. Effect of Carbachol on $\left[\mathrm{Ca}^{2+}\right]_{\mathrm{i}}$ in Cultured Gastric Epithelial Cells

The photograph (A) shows the micrograph $(\times 400)$ of a cell layer stained with the PAS method and the $\left[\mathrm{Ca}^{2+}\right]_{\mathrm{i}}$ imaging $(\mathrm{B})$ after addition of carbachol $\left(1 \times 10^{-4} \mathrm{M}\right)$. $(\mathrm{C})$ represents changes in the ratio at the area of $\mathrm{a}, \mathrm{b}$, and $\mathrm{c}$ with time. Carbachol was added to the culture dishes at the arrow. Each line represents the change in fluorescence ratio at three different parts of a cell layer (a, b, and c shown in (B)). After measurement of the fluorescence ratio, cells were stained with the PAS method.

doses of A23187, PMA, and dbcAMP, respectively. The effects of combined administration of these substances are shown in Table 2. Mucus secretion was synergistically induced by combined stimulation with these secretagogues, and the amount of secreted mucus was markedly more than the summation of individual secretagogue-induced mucus secretion.

Effects of Secretagogues on Intracellular cAMP Concentration The effects of carbachol, CCK-8, $\mathrm{PGE}_{2}$, and secretin on the intracellular cAMP accumulation in cultured gastric epithelial cells were estimated in the presence of IBMX (Table 3). Forskolin, an adenylate cyclase activator, markedly stimulated cAMP accumulation in gastric epithelial cells. Secretin and $\mathrm{PGE}_{2}$ stimulated cAMP accumulation significantly. However, carbachol and CCK-8 did not stimulate it, nor did gastrin I and histamine (data not shown).

Effects of Carbachol and CCK-8 on $\left[\mathrm{Ca}^{2+}\right]_{i}$ in Gastric Epithelial Cells The effects of carbachol and CCK-8 on $\left[\mathrm{Ca}^{2+}\right]_{\mathrm{i}}$ in gastric epithelial cells were investigated. When the cultured cells were incubated with carbachol, an increase in the fluorescence ratio $(340 \mathrm{~nm} / 380 \mathrm{~nm})$ of fura- 2 in a cell layer (about 10 cells) was observed (Fig. 2). After measurement of $\left[\mathrm{Ca}^{2+}\right]_{\mathrm{i}}$, the cells were stained with the periodic acidSchiff (PAS) method. All cells in which $\left[\mathrm{Ca}^{2+}\right]_{i}$ was in- creased by carbachol were PAS positive (Fig. 2(A)). Figure 2(C) shows the changes in the fluorescence ratio in three cells in one cell layer with time, in which synchronized changes in the ratio were observed in the neighboring parts (a) and (b) in Fig. 2(B). However, an independent $\left[\mathrm{Ca}^{2+}\right]_{\mathrm{i}}$ increase was seen in part (c) on the opposite side of the cell layer.

CCK-8 also induced a $\left[\mathrm{Ca}^{2+}\right]_{\mathrm{i}}$ increase in a cultured epithelial cell, in which a transient $\left[\mathrm{Ca}^{2+}\right]_{\mathrm{i}}$ increase was seen (Fig. 3). However, secretin and $\mathrm{PGE}_{2}$ did not induce a $\left[\mathrm{Ca}^{2+}\right]_{\mathrm{i}}$ increase (Fig. 3).

Effects of Protein Kinase $A$ and $C$ Inhibitors and Intracellular Calcium Chelator on Secretagogue-Induced Mucus Secretion Table 4 shows the effects of (A) H-89 (a protein kinase A inhibitor), (B) chelerythrine (a protein kinase $\mathrm{C}$ inhibitor), and (C) BAPTA-AM (an intracellular calcium chelator) on secretagogue-induced mucus secretion. $\mathrm{H}-$ 89 significantly inhibited dbcAMP-, $\mathrm{PGE}_{2}-$, and secretin-induced mucus secretion. However, it did not inhibit carbacholand CCK-8-induced mucus secretion. Chelerythrine significantly inhibited PMS-, carbachol-, and CCK-8-induced mucus secretion, but not $\mathrm{PGE}_{2}$ - and secretin-induced secretion. On the other hand, BAPTA-AM significantly inhibited mucus secretion induced by all the secretagogues investi- 


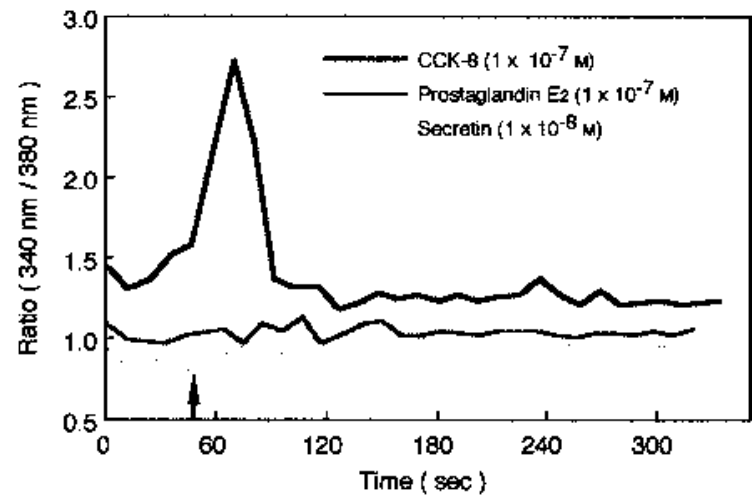

Fig. 3. Effects of CCK-8, Secretin, and $\mathrm{PGE}_{2}$ on $\left[\mathrm{Ca}^{2+}\right]_{\mathrm{i}}$ in Cultured Gastric Epithelial Cells

CCK-8 $\left(1 \times 10^{-7} \mathrm{M}\right)$, secretin $\left(1 \times 10^{-8} \mathrm{M}\right)$, or $\mathrm{PGE}_{2}\left(1 \times 10^{-7} \mathrm{M}\right)$ was added to the culture medium at the arrow, respectively. Each ratio is shown with time. CCK-8 induced $\left[\mathrm{Ca}^{2+}\right]_{\mathrm{i}}$ increase.

gated. BAPTA-AM inhibited $89 \%, 81 \%$, and $86 \%$ of A23187-, carbachol-, and CCK-8-induced mucus secretion, and $58 \%$ and $58 \%$ of $\mathrm{PGE}_{2}$ - and secretin-induced secretion, respectively.

\section{DISCUSSION}

We investigated the effects of second mediators of various secretagogues on mucus secretion from rat cultured gastric epithelial cells. For this purpose, we chose carbachol, CCK8, secretin, and $\mathrm{PGE}_{2}$ as agonists for the receptors, and dbcAMP, PMA, and A23187 as second mediator-like substances. When cells receive different kinds of stimuli concomitantly, they usually respond synergistically. However, combined administration of paired receptor agonists stimulated mucus secretion not synergistically but additively. On the other hand, combined administration of second mediatorlike substances stimulated mucus secretion synergistically. These results suggest that the receptors for mucus secretion interact with each other. We reported on receptor-receptor interactions in our previous paper. ${ }^{8}$ It is thought that many gastrointestinal hormones and physiologically active substances act concurrently on the same digestive organs after meals. If these substances stimulate mucus secretion synergistically, huge amounts of mucus must be secreted. Mucus should protect the gastric mucosa in any situation, and therefore a regulatory system that prevents exhaustion of the mucus supply might operate on the gastrointestinal mucosa.

The carbachol- and CCK-8-induced PI turnover in gastric epithelial cells had already been demonstrated. ${ }^{4)}$ We also investigated $\left[\mathrm{Ca}^{2+}\right]_{\mathrm{i}}$ and diacylglycerol (DG) levels in this study. Since Seidler and Pfeiffer ${ }^{5)}$ mentioned that the $\left[\mathrm{Ca}^{2+}\right]_{\mathrm{i}}$ increase in gastric mucous cells was lower than that in chief cells or parietal cells, an improved method for $\left[\mathrm{Ca}^{2+}\right]_{\mathrm{i}}$ measurement in the cells was necessary. We employed a microscopic technique using 2-day cultured cell layer adhering to collagen gel. To obtain direct evidence of the $\left[\mathrm{Ca}^{2+}\right]_{\mathrm{i}}$ increase induced by carbachol and CCK-8, we inoculated gastric epithelial cells so as to form small cell layers for high incorporation of fura-2-AM into the cells, because sometimes the enhanced $\left[\mathrm{Ca}^{2+}\right]_{\mathrm{i}}$ increase was only seen at the edge of a large cell layer. In this manner, we could observe changes in the
Table 4A. Effects of H-89 on Mucus Secretion from Cultured Gastric Epithelial Cells Stimulated by dbcAMP, Carbachol, CCK-8, $\mathrm{PGE}_{2}$, and Secretin

\begin{tabular}{lcccc}
\hline \hline & Basal & Chemical & $\begin{array}{c}\text { with } \\
\mathrm{H}-89^{a)}\end{array}$ & $\begin{array}{c}\text { Inhibition } \\
(\%)\end{array}$ \\
\hline $\begin{array}{c}\text { dbcAMP } \\
\left(1 \times 10^{-3} \mathrm{M}\right)\end{array}$ & $2.14 \pm 0.38$ & $7.44 \pm 0.78$ & $4.91 \pm 0.59^{*}$ & $46 \pm 9$ \\
$\begin{array}{c}\text { Carbachol } \\
\left(1 \times 10^{-4} \mathrm{M}\right)\end{array}$ & $2.53 \pm 0.28$ & $5.60 \pm 0.37$ & $5.10 \pm 0.54$ & - \\
$\begin{array}{c}\mathrm{CCK}-8 \\
\left(1 \times 10^{-7} \mathrm{M}\right)\end{array}$ & $2.82 \pm 0.09$ & $5.54 \pm 0.20$ & $6.34 \pm 0.63$ & - \\
$\begin{array}{c}\mathrm{PGE}_{2} \\
\left(1 \times 10^{-7} \mathrm{M}\right)\end{array}$ & $2.04 \pm 0.24$ & $7.50 \pm 0.51$ & $4.54 \pm 0.78^{*}$ & $56 \pm 14$ \\
$\begin{array}{c}\mathrm{Secretin} \\
\left(1 \times 10^{-8} \mathrm{M}\right)\end{array}$ & $2.59 \pm 0.53$ & $6.77 \pm 0.80$ & $3.58 \pm 0.78^{*}$ & $78 \pm 13$ \\
& & & &
\end{tabular}

a) H-89: $1 \times 10^{-7}$ M. Each value is $\%$ of total and is the mean \pm S.E. of 4 or 5 separate experiments. $* p<0.05$ compared with the stimulated control.

Table 4B. Effects of Chelerythrine on Mucus Secretion from Cultured Gastric Epithelial Cells Stimulated by PMA, Carbachol, CCK-8, PGE 2 , and Secretin

\begin{tabular}{lcccc}
\hline \hline & Basal & Chemical & $\begin{array}{c}\text { with } \\
\text { Chelerythrine }\end{array}$ & $\begin{array}{c}\text { Inhibition } \\
(\%)\end{array}$ \\
\hline $\begin{array}{l}\text { PMA } \\
\left(1 \times 10^{-9} \mathrm{M}\right)\end{array}$ & $2.68 \pm 0.22$ & $10.70 \pm 0.90$ & $7.12 \pm 0.93^{*}$ & $46 \pm 11$ \\
$\begin{array}{c}\text { Carbachol } \\
\left(1 \times 10^{-4} \mathrm{M}\right)\end{array}$ & $2.95 \pm 0.34$ & $7.77 \pm 0.45$ & $4.79 \pm 0.45^{* *}$ & $61 \pm 15$ \\
$\begin{array}{c}\text { CCK-8 } \\
\left(1 \times 10^{-7} \mathrm{M}\right)\end{array}$ & $2.60 \pm 0.23$ & $7.60 \pm 0.67$ & $3.82 \pm 0.69 * *$ & $76 \pm 12$ \\
$\begin{array}{c}\text { PGE } \\
\left(1 \times 10^{-7} \mathrm{M}\right)\end{array}$ & $2.22 \pm 0.27$ & $7.38 \pm 1.01$ & $6.38 \pm 0.28$ & - \\
$\begin{array}{c}\text { Secretin } \\
\left(1 \times 10^{-8} \mathrm{M}\right)\end{array}$ & $2.17 \pm 0.34$ & $6.35 \pm 0.79$ & $5.85 \pm 0.74$ & - \\
& & & &
\end{tabular}

a) Chelerythrine: $1 \times 10^{-7} \mathrm{M}$. Each value is $\%$ of total and is the mean \pm S.E. of 4 or 5 separate experiments. $* p<0.05 ; * * p<0.01$ compared with the stimulated control.

Table 4C. Effects of BAPTA-AM on Mucus Secretion from Cultured Gastric Epithelial Cells Stimulated by A23187, PMA, Carbachol, CCK-8, PGE 2 , and Secretin

\begin{tabular}{|c|c|c|c|c|}
\hline & Basal & Chemical & $\begin{array}{c}\text { with } \\
\text { BAPTA-AM }^{a)}\end{array}$ & $\begin{array}{c}\text { Inhibition } \\
(\%)\end{array}$ \\
\hline $\begin{array}{l}\text { A23187 } \\
\quad\left(1 \times 10^{-6} \mathrm{M}\right)\end{array}$ & $1.86 \pm 0.20$ & $5.45 \pm 0.19$ & $2.16 \pm 0.27^{*}$ & $89 \pm 5$ \\
\hline $\begin{array}{l}\text { PMA } \\
\qquad\left(1 \times 10^{-9} \mathrm{M}\right)\end{array}$ & $1.90 \pm 0.32$ & $5.64 \pm 0.41$ & $3.38 \pm 0.54 *$ & $61 \pm 10$ \\
\hline $\begin{array}{l}\text { Carbachol } \\
\qquad\left(1 \times 10^{-4} \mathrm{M}\right)\end{array}$ & $2.33 \pm 0.12$ & $5.19 \pm 0.67$ & $2.84 \pm 0.21 *$ & $81 \pm 6$ \\
\hline $\begin{array}{l}\text { CCK-8 } \\
\qquad\left(1 \times 10^{-7} \mathrm{M}\right)\end{array}$ & $2.22 \pm 0.18$ & $5.09 \pm 0.41$ & $2.41 \pm 0.79 *$ & $86 \pm 14$ \\
\hline $\begin{array}{l}\mathrm{PGE}_{2} \\
\qquad\left(1 \times 10^{-7} \mathrm{M}\right)\end{array}$ & $2.06 \pm 0.32$ & $5.77 \pm 0.42$ & $3.77 \pm 0.41 *$ & $57 \pm 16$ \\
\hline $\begin{array}{l}\text { Secretin } \\
\qquad\left(1 \times 10^{-8} \mathrm{M}\right)\end{array}$ & $1.90 \pm 0.22$ & $4.10 \pm 0.33$ & $2.86 \pm 0.23 *$ & $58 \pm 18$ \\
\hline
\end{tabular}

a) BAPTA-AM: $1 \times 10^{-5} \mathrm{M}$. Each value is $\%$ of total and is the mean + S.E. of 4 or 5 separate experiments. $* p<0.05$ compared with the stimulated control.

fluorescence ratio in the cultured gastric epithelial cells with carbachol and CCK-8. Carbachol induced changes in $\left[\mathrm{Ca}^{2+}\right]_{i}$ which were synchronized with those in a neighboring cell. Therefore it was thought that a tight junction between cells in a cell layer was formed. However, even at high concentration, 
secretin and $\mathrm{PGE}_{2}$ did not induce a $\left[\mathrm{Ca}^{2+}\right]_{\mathrm{i}}$ increase.

Forskolin strongly stimulated cAMP accumulation in the gastric epithelial cells and weakly stimulated mucus secretion. Both secretin and $\mathrm{PGE}_{2}$ stimulated mucus secretion more strongly than forskolin, although they induced less cAMP accumulation than forskolin. From the discrepancy between the amount of cAMP and secreted mucus, it is suggested that secretin and $\mathrm{PGE}_{2}$ stimulate mucus secretion by involving certain intracellular changes other than cAMP.

To confirm the second mediators of mucus secretion, we used second mediator-specific inhibitors. Table 4 (A, B, and C) shows that carbachol and CCK-8 stimulated mucus secretion through protein kinase $\mathrm{C}$ activation and $\left[\mathrm{Ca}^{2+}\right]_{\mathrm{i}}$ increase, and secretin and $\mathrm{PGE}_{2}$ stimulated it through protein kinase $\mathrm{A}$ activation. However, the $\mathrm{Ca}^{2+}$ chelator also inhibited secretin- and $\mathrm{PGE}_{2}$-induced mucus secretion. These results suggest that secretin and $\mathrm{PGE}_{2}$ stimulate mucus secretion through cAMP accumulation and a $\mathrm{Ca}^{2+}$-associated pathway. Delvalle et al. ${ }^{9}$ ) showed that activation of histamine $\mathrm{H}_{2}$ receptor induced both cAMP accumulation and $\left[\mathrm{Ca}^{2+}\right]_{\mathrm{i}}$ increase in histamine $\mathrm{H}_{2}$ receptor-transfected hepatoma-derived cells, and the $\left[\mathrm{Ca}^{2+}\right]_{\mathrm{i}}$ increase was induced by the histamine receptor-associated G-protein. ${ }^{9)}$ It was also reported in rat pancreatic acinar cells that secretin stimulated both cAMP accumulation and inositol trisphosphate production. ${ }^{10)}$ Taking those reports and our results into consideration, it is suggested that an undetectable $\left[\mathrm{Ca}^{2+}\right]_{\mathrm{i}}$ increase occurred accompanied by receptor-associated cAMP accumulation. Since a sufficient amount of mucus secretion was not induced by dbcAMP or forskolin, secretin and $\mathrm{PGE}_{2}$ would induce the $\left[\mathrm{Ca}^{2+}\right]_{i}$ increase through G-protein. It was reported that phosphorylation of the membrane-cytoskeletal linker by protein kinase A and promotion of vesicular motor activity by $\mathrm{Ca}^{2+}$-activated protein kinase play an important role in the formation of se- cretory canaliculus by the fusion of tubulovesicles and the apical membrane in parietal cells. ${ }^{11)}$ A similar mechanism would proceed in mucus secretion. However, it should also be noted that cAMP plays various roles at low $\left[\mathrm{Ca}^{2+}\right]_{\mathrm{i}}$. Much research is necessary to clarify the interaction between cAMP and $\left[\mathrm{Ca}^{2+}\right]_{\mathrm{i}}$ in mucus secretion.

In conclusion, carbachol and CCK-8 stimulate mucus secretion from gastric epithelial cells through the $\left[\mathrm{Ca}^{2+}\right]_{i}$ increase, and probably protein kinase $\mathrm{C}$ activation, and secretin and $\mathrm{PGE}_{2}$ stimulate it through cAMP accumulation and the $\left[\mathrm{Ca}^{2+}\right]_{\mathrm{i}}$-associated pathway. In the physiological state, many gastrointestinal hormones, autacoids, and neurotransmitters act concomitantly, and mucus cells secretion in high intracellular cAMP and $\left[\mathrm{Ca}^{2+}\right]_{\mathrm{i}}$ conditions is regulated interactively.

\section{REFERENCES}

1) Tani S., Okuda M., Morishige R., Tanaka T., Biol. Pharm. Bull., 20, 482-485 (1997).

2) Keates A. C., Hanson P. J., J. Physiol. (London), 423, 397-409 (1990).

3) Fortner J. F., Fortner G. G., "Physiology of the Gastrointestinal Tract," ed. by Johnson L. R., Raven Press, New York, 1994, pp. 1255-1283.

4) Bell W., Bersimbaev R., Sewing K. F., Biomed. Biochem. Acta, 50, 1185-1192 (1991)

5) Seidler U., Pfeiffer A., Am. J. Physiol., 260, G133-G141 (1991).

6) Brown J. F., Keates A. C., Hanson P. J., Whittle B. J. R., Am. J. Physiol., 265, G418-G422 (1993).

7) Sugaya A., Tsuda T., Kubota K., Motoki M., Sugaya E., Bioimages, 1, $115-123$ (1993).

8) Tanaka T., Tani S., Biol. Pharm. Bull., 17, 415-418 (1994).

9) Delvalle J., Wang L., Gantz I., Yamada T., Am. J. Physiol., 263, G967-G972 (1992).

10) Trimble E. R., Bruzzone R., Biden T. J., Meehan C. J., Andreu D., Merrifield R. B., Proc. Natl. Acad. Sci. U.S.A., 84, 3146-3150 (1987).

11) Urushidani T., Hanzel D. K., Forte J. G., Am. J. Physiol., 256, G1070-G1081 (1989). 